\title{
Epigenetic Mechanisms and the Mismatch Concept of the Developmental Origins of Health and Disease
}

\author{
KEITH M. GODFREY, KAREN A. LILLYCROP, GRAHAM C. BURDGE, PETER D. GLUCKMAN, AND MARK A. HANSON \\ Centre for Developmental Origins of Health and Disease [K.M.G., K.A.L., G.C.B., M.A.H.], University of Southampton, Southampton \\ SO16 5YA, United Kingdom; Liggins Institute and National Research Centre for Growth and Development [P.D.G.], University of \\ Auckland, Private Bag 92019, Auckland, New Zealand
}

\begin{abstract}
There is now considerable evidence that elements of the heritable or familial component of disease susceptibility are transmitted by nongenomic means, and that environmental influences acting during early development shape disease risk in later life. The underlying mechanisms are thought to involve epigenetic modifications in nonimprinted genes induced by aspects of the developmental environment, which modify gene expression without altering DNA sequences. These changes result in life-long alterations in gene expression. Such nongenomic tuning of phenotype through developmental plasticity has adaptive value because it attempts to match an individual's responses to the environment predicted to be experienced. When the responses are mismatched, disease risk increases. An example of such mismatch is that arising either from inaccurate nutritional cues from the mother or placenta before birth, or from rapid environmental change through improved socioeconomic conditions, which contribute substantially to the increasing prevalence of type-2 diabetes, obesity, and cardiovascular disease. Recent evidence suggests that the effects can be transmitted to more than the immediately succeeding generation, through female and perhaps male lines. Future research into epigenetic processes may permit us to develop intervention strategies. (Pediatr Res 61: 5R-10R, 2007)
\end{abstract}

$\mathrm{E}$ pidemiologic studies have demonstrated a robust association between small size at birth and during infancy, and a greater risk of chronic disease including coronary heart disease, hypertension, stroke, type 2 diabetes, and osteoporosis in later life (1). It is now accepted that the associations do not reflect confounding by adult environmental risk factors such as smoking or socioeconomic status, and the original observations from the Southampton group have been extensively replicated worldwide (1). A recent meta-analysis of 18 studies reported that the relative risk of adult coronary heart disease was 0.84 for each $1 \mathrm{~kg}$ increase in birth weight (2). This value is likely to substantially underestimate the developmental influence as there is much experimental evidence that the prenatal environment can induce long-term cardiovascular effects without necessarily affecting size at birth (3). Moreover, profound effects have now been demonstrated if there is a "mismatch" between the early, developmental en-

Received November 14, 2006; accepted January 9, 2007.

Correspondence: Mark A. Hanson, Ph.D., Centre for Developmental Origins of Health and Disease, Princess Anne Hospital (Mailpoint 887), Coxford Road, Southampton SO16 5YA, UK; e-mail: m.hanson@soton.ac.uk

M.A.H. is supported by the British Heart Foundation.

DOI: $10.1203 / p d r .0 b 013 e 318045 b e d b$ vironment and the subsequent environment in childhood and adult life (4). These and other observations have resulted in wide recognition that the "Developmental Origins of Health and Disease" has major public health implications worldwide. For example, a recent World Health Organization Technical Consultation concluded, "The global burden of death, disability, and loss of human capital as a result of impaired fetal development is huge and affects both developed and developing countries" (5). The report advocates a move away from simply low birth weight, to broader considerations of maternal well-being, and achieving the optimal environment for the fetus to maximize its potential for a full and healthy life.

In parallel with the epidemiologic observations, animal studies have demonstrated the importance of epigenetic changes in mediating the effects on adult phenotype and physiology arising from perturbations of the developmental environment, including maternal diet $(6,7)$, uterine blood flow (8), and maternal nursing behavior (9). The role of epigenetic processes in the early stages of some forms of cancer is well established (10), but we are only now starting to appreciate that epigenetic processes also have major implications for our understanding of evolutionary mechanisms and for human development, reproduction, and degenerative disease. The effects on the offspring of epigenetic changes during development in animals mimic aspects of human disease, for example, metabolic disease, impaired renal function, or exaggerated stress responses, and a coherent theory for a role of epigenetic mechanisms in the developmental origins of later chronic disease is emerging. This is the subject of this review.

\section{MISMATCH, DEVELOPMENTAL PLASTICITY, AND EPIGENETICS}

Steep temporal trends in the incidence rates of cardiovascular disease in many populations suggest that the epidemiologic associations are unlikely to have arisen exclusively through the pleiotropic effects of genes that influence both fetal growth and later cardiovascular risk. In contrast, the effects are now viewed as the result of the phenotype estab-

\footnotetext{
Abbreviations: Dnmt, DNA methyltransferase; CpG, cytosine and guanine adjacent to each other in the genome, linked by a phosphodiester bond; GR, glucocorticoid receptor; HDAC, histone deacetylase; HMT, histone methyltransferase; PPAR, peroxisome proliferator-activated receptor; RNS Pol, RNA polymerase; $\mathbf{T F}$, transcription factor
} 
lished by the interaction between genes and the developmental environment using the processes of developmental plasticity (11-13). As in other species, developmental plasticity attempts to "tune" gene expression to produce a phenotype best suited to the predicted later environment (14). When the resulting phenotype is matched to its environment, the organism will remain healthy. When there is a mismatch, the individual's ability to respond to environmental challenges may be inadequate and risk of disease increases. Thus, the degree of the mismatch determines the individual's susceptibility to chronic disease (4).

The degree of mismatch can by definition be increased by either poorer environmental conditions during development, or richer conditions later, or both (4). Unbalanced maternal diet, body composition, or disease can perturb the former; the rapid increase in energy-dense foods and reduced physical activity levels associated with a western lifestyle will increase the degree of mismatch via the latter (Fig. 1). Such changes are of considerable importance in developing societies going through rapid socioeconomic transitions. In this review, we focus on the epigenetic components of such inherited risk of disease, while noting that other, nongenomic mechanisms also operate to alter risk of disease in subsequent generations, e.g. the passage of cultural risk factors such as smoking.

The processes of phenotypic induction through developmental plasticity produce integrated changes in a range of organs via epigenetic processes. They establish a life-course strategy for meeting the demands of the predicted later environment (15). This explains why an impaired early environment produces a range of effects-alterations in cardiovascular and metabolic homeostasis, growth and body composition, cognitive and behavioral development, reproductive function,

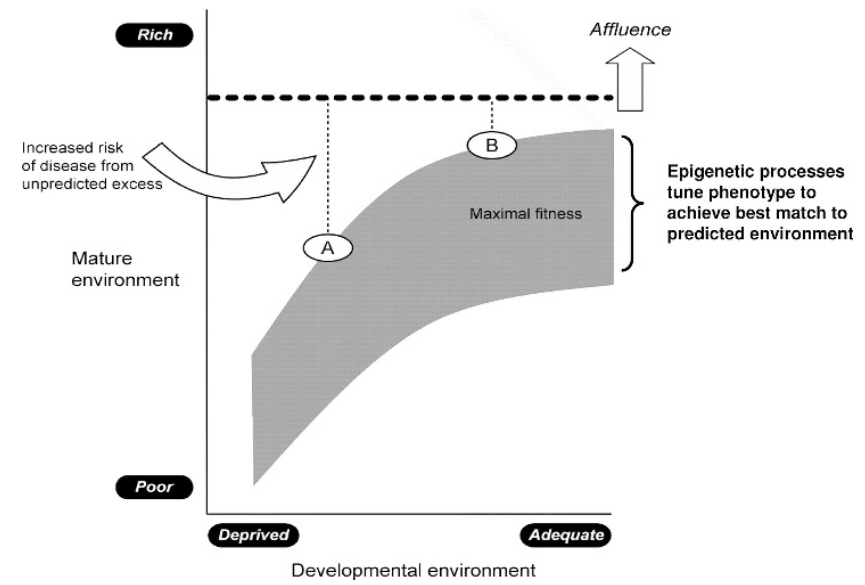

Figure 1. The mismatch concept emphasizes that the degree of disparity between the environment experienced during development and that experienced later influences the risk of disease. During the period of developmental plasticity in prenatal and early postnatal life, epigenetic processes are thought to alter gene expression to produce phenotypic attributes best suited to the environment in which the individual predicts that it will live, based on environmental cues transmitted via the mother. Greater mismatch gives greater risk of disease from unpredicted excessive richness (high calorie density food, sedentary lifestyle) of the environment. Thus, risk is greater with poorer developmental environment ( $A$ vs $B$ ), and with socioeconomic transitions to an affluent western lifestyle. Adapted from Gluckman PD et al. 2007 Am J Hum Biol 19:1-19 @ 2006 Wiley- Liss,Inc., with permission. repair processes and longevity—some of which are associated with increased risk of cardiovascular and metabolic disease, "precocious" puberty, osteoporosis, and some forms of cancer. Understanding the underlying epigenetic processes thus holds the key to understanding the underlying pathophysiology and to developing approaches to early diagnosis, prevention and treatment of these diseases.

\section{EPIGENETIC PROCESSES-DEFINITION AND MECHANISMS}

The term "epigenetic" was coined by Waddington (16) to refer to the ways in which the developmental environment can influence the mature phenotype. His work and that of others (17) on developmental plasticity stemmed from observations that environmental influences during development could induce alternative phenotypes from a genotype, some of the clearest examples being polyphenisms in insects (18). Such processes can, however, also induce a gradation of phenotypes, constituting a population reaction norm (19). Waddington showed in Drosophila melanogaster that wing vein pattern could be affected by heat shock treatment of the pupae (20). Breeding individuals with these environmentally induced changes led eventually to a stable population exhibiting the phenotype without the environmental stimulus. Waddington termed this "genetic assimilation." Such work, largely overlooked by proponents of the modern synthesis of genetic and evolutionary biology (21), demonstrates a dynamic interaction between the genome and the environment during the plastic phase of development, producing effects that can be heritable (11) in terms of an environmental cue acting in one generation having effects that are manifest in subsequent generations.

The term "epigenetic" is now used to refer to structural changes to genes that do not alter the nucleotide sequence, with epigenetic inheritance being defined as biologic processes that regulate mitotically or meiotically heritable changes in gene expression without altering the DNA sequence (22). Of particular relevance is methylation of specific $\mathrm{CpG}$ dinucleotides in gene promoters and alterations in DNA packaging arising from chemical modifications of the chromatin histone core around which DNA wraps (Fig. 2). The modifications include acetylation, methylation, ubiquitination, and phosphorylation. Such epigenetic inheritance systems (23) can be random with respect to the environment and have been termed "epimutations" (24), or specific epigenetic changes can be induced by the environment (25) (Fig. 3).

Epigenetic mechanisms are widely implicated in cancer (10). Promoter methylation is important for asymmetrical silencing of imprinted genes (26) and retrotransposons $(27,28)$. However, they also play a critical role in a range of developmental processes. With the exception of imprinted genes, widespread removal of epigenetic marks occurs following fertilization when maternal and paternal genomes undergo extensive demethylation to ensure pluripotency of the developing zygote. This is followed by de novo methylation just before implantation $(29,30)$. About $70 \%$ of CpGs are methylated, mainly in repressive heterochromatin regions and in repetitive sequences such as retrotransposable elements (31). 




Figure 2. Epigenetic silencing of transcription. When $\mathrm{CpG}$ dinucleotides are unmethylated in the promoter, RNA Pol and TF can bind to specific nucleotide sequences and the coding region (exon) is transcribed. Methylation of CpGs by the activity of Dnmt enables recruitment of methyl CpG binding protein-2 (MeCP2), which in turn recruits HDAC/ HMT to form an enzyme complex bound to the gene promoter. The MeCP2/HDAC/HMT complex removes acetyl groups from histones and catalyses di- and tri- methylation of specific lysine residues which causes the DNA to condense. This prevents access of RNA polymerase and transcription factors to DNA and so converts transcriptionally active euchromatin to inactive heterochromatin. Thus, the overall effect of DNA and histone methylation is to induce long-term silencing of transcription.



Figure 3. Developmental plasticity declines and exposure to environmental challenges increases with age. Epigenetic processes are induced by cues from the developmental environment. They play a role in determining the phenotype of the offspring as part of a life-course strategy to match it to its environment. If not appropriately matched, the risk of later disease is increased.

DNA methylation also plays a key role in cell differentiation by silencing the expression of specific genes during the development and differentiation of individual tissues. For example, the expression of the homeobox gene Oct-4, a key regulator of cellular pluripotency in the early embryo, is permanently silenced by hypermethylation of its promoter around E6.5 in the mouse (32), whereas HoxA5 and HoxB5, which are required for later stages of development, are not methylated and silenced until early postnatal life (33). For some genes there also appear to be gradations of promoter demethylation associated with developmental changes in role of the gene product. The $\delta$-crystallin II and phosphoenolpyruvate carboxykinase promoters are methylated in the early embryo but undergo progressive demethylation during fetal development, and are hypomethylated compared with the embryo and expressed in the adult $(34,35)$. Thus, changes in methylation that are associated with cell differentiation and functional changes are established at different times during development of the embryo. The pattern of DNA methylation is copied during mitosis by Dnmt- 1 activity. This provides an "epigenetic memory" of patterns of gene regulation, and hence cell function, which is established during development and which is passed to the adult (29). This immediately suggests a mechanism by which the environment may induce stable changes to cell function that persist in the adult organism, by which environmental challenges at different times during development may produce different phenotypic outcomes and in humans differential risk of disease.

Genomic imprinting represents a special case of epigenetic regulation of genes (36). Through imprinting (which bears no relation to the term for behavioral conditioning defined by Lorenz), heritable patterns of gene expression are induced without changes in the sequence of genomic DNA through the silencing of one set of alleles dependent on its parental gender origin. Disease resulting from imprinting disorders is well recognized, e.g. Beckwith-Wiedemann syndrome. Although rare, the incidence of this disorder is increased in offspring conceived by assisted reproductive techniques (37). Imprinting is most frequently mediated by allele-specific DNA methylation, although imprinted alleles may differ in other ways.

Small noncoding regulatory RNA regulation of gene expression is a newly emerging epigenetic mechanism (25). These microRNAs have been shown to not only modulate the stability and translation of mRNAs, but also can induce gene silencing through the induction of gene methylation and alterations in chromatin structure. However, whether early life environmental challenges such as maternal nutritional constraints can alter the expression or formation of these microRNAs in the offspring has yet to be discovered, and the precise role that these microRNAs play in the developmental origins of adult disease remains to be determined.

\section{EVIDENCE FOR NONGENOMIC INHERITANCE IN HUMANS}

Human studies have provided a number of lines of evidence suggesting transgenerational nongenomic inheritance, although it is inevitably difficult to define the relative contributions of genetic, epigenetic, and common environmental or learned behavioral factors. For example, patterns of smoking, diet, and exercise can affect risk across more than one generation (38) by several mechanisms. Strong evidence for transgenerational nongenomic inheritance exists for dietary and endocrine exposures. Records from Överkalix in northern Sweden for individuals born in 1890, 1905, and 1920 have shown that diabetes mortality increased in men if the paternal grandfather was exposed to abundant nutrition during his prepubertal growth period (39), an effect later extended to paternal grandmother/granddaughter pairs and transmitted in a gender-specific fashion (40). During the 1944/1945 famine in the Netherlands, previously adequately nourished women 
were subjected to low caloric intake and associated environmental stress. Pregnant women exposed to famine in late pregnancy gave birth to smaller babies (41) who had an increased risk of later insulin resistance (42). Famine exposure at different stages of gestation was variously associated with an increased risk of obesity, dyslipidemia, and coronary heart disease, and F2 offspring of females exposed in the first trimester in utero did not have the expected increase in birth weight with increasing birth order (41). Exposure of pregnant women to diethylstilbestrol led to a marked increase in reproductive abnormalities and uterine fibroids (43), an earlier menopause (44), and breast (45) and rare genital tract cancers in their children, and there is evidence of third-generational effects transmitted through the maternal line (46).

\section{EVIDENCE OF EPIGENETIC MECHANISMS IN ANIMALS}

Animal research has given us new insights into developmental plasticity and epigenetics. First, it is clear that such epigenetic effects during development produce graded changes in the expression of a range of genes, in addition to those that produce parent-specific effects mediated via imprinted genes. Feeding a reduced protein diet to pregnant rats induces permanent changes in gene expression in the offspring; GR and PPAR $\alpha$ expression is increased in the liver $(7,47)$, whereas expression of the enzyme that inactivates corticosteroids, $11 \beta$-hydroxysteroid dehydrogenase type II, is reduced in liver, lung, kidney, and brain (48). In the liver, increased GR and PPAR $\alpha$ expression is due to hypomethylation of their respective promoters (7). The PPAR $\alpha$ promoter is also hypomethylated in the heart (49). In contrast, there was no difference in methylation of the PPAR $\gamma 1$ promoter in the liver, which suggests that the changes in epigenetic regulation induced by the maternal reduced protein diet were genespecific (7). Graded silencing of the retrotransposon IAP element that regulates the agouti phenotype has been shown in the offspring of mice fed diets with different amounts of folic acid during pregnancy (6). Nondietary factors also induce altered epigenetic regulation of genes. Epigenetic changes in the methylation of renal p53 are produced by uterine blood flow restriction and are associated with reduced nephron number (8), which may precede the development of hypertension (50). Variations in maternal behavior also lead to epigenetic changes; in rats, maternal care of the pups influences methylation of the estrogen receptor-alphalb (51) and the hippocampal $\mathrm{GR}_{7}$ promoters (9), the latter resulting in changes in hypothalamic-pituitary-adrenal axis stress responses (9). This study illustrates that epigenetic changes can be induced in later stages of developmental plasticity, such as during early postnatal life.

The levels of methylation of $\mathrm{CpG}$ bases in the genome are controlled in part by the activity of Dnmts. The developmental effects observed in the rat are not produced by changes in the expression of Dnmt-3a or $b$, or in the activity of methyl binding domain protein-2 (52), revealing that they are not produced by changes in the demethylation/remethylation processes that occur soon after fertilization $(29,30)$. In contrast, they are accompanied by decreased Dnmt- 1 expression (52). This suggests a mechanism by which down-regulation of Dnmt-1 expression during early development leads to a progressive loss of epigenetic memory and an altered adult phenotype. This accords with the effects of nutritional or endocrine challenges during early gestation in altering growth of organs such as the heart and liver $(53,54)$ and producing later effects on cardiovascular and metabolic control (55-57). In the rat, the epigenetic effects appear to be dependent on 1-carbon metabolism. Supplementation of the reduced protein diet with folic acid during pregnancy prevents cardiovascular changes in the offspring (58) and normalizes the changes in GR and PPAR $\alpha$ promoter methylation and gene expression (7) and in Dnmt-1 binding and expression (52). Induction of elevated blood pressure or endothelial dysfunction in the offspring is also prevented by maternal supplementation with glycine, but not with alanine or urea $(59,60)$, supporting the concept that methyl group provision is important.

Furthermore, recent data show that both the effects of glucocorticoid treatment and the reduced protein diet in pregnancy can be passed to the second generation without further nutritional or endocrine manipulation $(58,61,62)$. Feeding rats a reduced protein diet during pregnancy in the F0 generation induces hypomethylation of the PPAR $\alpha$ and GR promoters in the livers of both the F1 and F2 male offspring (62). This shows that transmission of induced phenotypes between generations involves altered epigenetic regulation of specific genes.

\section{ADAPTIVE VALUE OF NONGENOMIC INHERITANCE}

The increasing evidence for nongenomic inheritance and particularly epigenetic inheritance raises the question of why the processes underpinning it have been preserved through evolution. Natural selection is generally viewed as a process by which a species and its environment become well matched. Developmental plasticity utilizes environmental cues to adjust individual phenotype to the current and predicted environment $(13,63)$. These processes of developmental plasticity leading to nongenomic inheritance may have evolved to enhance fitness during shorter-term environmental shifts than Darwinian selection can necessarily cope with, and/or to ensure a greater match to a variable environment than selection alone can generate. In addition, it enables the induction of a wider range of phenotypes, permitting survival in a broader range of environments. Such strategies may have been important in the evolution of mammalian generalist species (64). Theoretical models demonstrate the circumstances under which fitness is enhanced if parents transmit information about the environment to their progeny. Factors to consider include the fidelity of the transmission of environmental cues, the degree of predictability of environmental conditions, and the costs of incorrect prediction $(63,65-67)$.

\section{RELEVANCE OF EPIGENETIC PROCESSES TO THE RISK OF ADULT DISEASE}

We now live much longer than our hominine ancestors. Thus, mechanisms selected for their advantage in our earlier 
evolution may no longer be advantageous or may be advantageous in the young and disadvantageous in the elderly. There are limits to the environment that the fetus can sense and use to adjust its development (68). Nongenomic epigenetic processes of transmitting environmental information between generations evolved to assist our evolution as we moved across changing environments. They may also have served to buffer critical aspects of our development, especially the vulnerable period of weaning in infancy, against shortterm environmental changes occurring between generations (69). Such processes were not designed to deal with the massive mismatch between the generally constrained fetal environment and the modern postnatal environment of highenergy intake and low energy expenditure (4) and disease risk is amplified by a greater mismatch between the prenatally predicted and actual adult environments. As a result, societies in rapid economic transition are particularly vulnerable (7073). Epigenetic and other nongenomic inheritance processes may have conferred survival advantage on evolving hominids; they now exacerbate risk of disease for several successive generations and play a major part in the current epidemics of metabolic and cardiovascular disease $(14,73)$. Additionally, the possibility is now being explored that exposure to xenobiotics such as endocrine disruptors may have multigenerational effects through female and male lines by actions on similar epigenetic mechanisms (74).

Lastly, returning to our starting point of population studies, we must note that there is increasing evidence for the effects of maternal obesity and gestational diabetes as risk factors for later metabolic and cardiovascular disease in the offspring $(75,76)$, a concept again supported by experimental studies in animals (77). These effects contribute to the increasing transgenerationally passed rising incidence of such disease in both developed and developing societies. The extent to which such risk of disease operates by epigenetic processes is not known.

\section{CONCLUSION}

Epigenetic changes provide a "memory" of developmental plastic responses to early environment. Their effects may only become manifest later in life, e.g. in terms of altered responses to environmental challenges. If the epigenetic change has occurred in part of the genome where gene expression is controlled by a transcription factor, then the consequences of the change will not become manifest until the transcription factor operates. There is additional potential for epigenetic marks to change throughout life as shown by recent studies on homozygous twins (78), and there is some evidence for inheritance of tissue-specific DNA methylation patterns (79). It is now important to conduct further research to determine the specific role of epigentic processes in the development of risk of cardiovascular and metabolic disease or other sequelae.

Acknowledgments. The authors thank Dr. Alan Beedle for his assistance with the literature search and editing of the manuscript.

\section{REFERENCES}

1. Godfrey KM 2006 The "Developmental Origins" hypothesis: epidemiology. In: Gluckman PD, Hanson MA (eds) Developmental Origins of Health and Disease-A Biomedical Perspective. Cambridge University Press, pp 6-32

2. Huxley R, Owen C, Whincup P, Cook D, Rich-Edwards J, Smith G 2007 Is birthweight a risk factor for coronary heart disease in later life? J Epidemiol (in press)

3. Hanson MA, Gluckman PD 2005 Developmental processes and the induction of cardiovascular function: conceptual aspects. J Physiol 565:27-34

4. Gluckman PD, Hanson MA 2006 Mismatch; How Our World No Longer Fits Our Bodies. Oxford University Press, Oxford

5. Promoting Optimal Fetal Development: Report of a Technical Consultation. World Health Organization. Available at: http://www.who.int/nutrition/topics/fetal_dev_report_EN.pdf

6. Waterland RA, Jirtle RL 2003 Transposable elements: targets for early nutritional effects on epigenetic gene regulation. Mol Cell Biol 23:5293-5300

7. Lillycrop KA, Phillips ES, Jackson AA, Hanson MA, Burdge GC 2005 Dietary protein restriction of pregnant rats induces and folic acid supplementation prevents epigenetic modification of hepatic gene expression in the offspring. J Nutr 135:13821386

8. Pham TD, MacLennan NK, Chiu CT, Laksana GS, Hsu JL, Lane RH 2003 Uteroplacental insufficiency increases apoptosis and alters p53 gene methylation in the full-term IUGR rat kidney. Am J Physiol Regul Integr Comp Physiol 285:R962R970

9. Weaver IC, Cervoni N, Champagne FA, D'Alessio AC, Sharma S, Seckl JR, Dymov S, Szyf M, Meaney MJ 2004 Epigenetic programming by maternal behavior. Nat Neurosci 7:847-854

10. Laird PW 2005 Cancer epigenetics. Hum Mol Genet 14:R65-R76

11. West-Eberhard MJ 2003 Developmental Plasticity and Evolution. Oxford University Press, New York

12. Bateson P, Barker D, Clutton-Brock T, Deb D, Foley RA, Gluckman P, Godfrey K, Kirkwood T, Mirazón Lahr M, Macnamara J, Metcalfe NB, Monaghan P, Spencer HG, Sultan SE 2004 Developmental plasticity and human health. Nature 430:419 421

13. Gluckman PD, Hanson MA, Spencer HG, Bateson P 2005 Environmental influences during development and their later consequences for health and disease: implications for the interpretation of empirical studies. Proc Biol Sci 272:671-677

14. Gluckman PD, Hanson MA 2004 Living with the past: evolution, development and patterns of disease. Science 305:1733-1736

15. Gluckman PD, Hanson MA, Beedle AS 2007 Early life events and their consequences for later disease; a life history and evolutionary perspective. Am J Hum Biol 19:1-19

16. Van Speybroeck L 2002 From epigenesis to epigenetics. The case of C.H. Waddington. Ann N Y Acad Sci 981:61-81

17. Schmalhausen I 1949 Factors of Evolution; the Theory of Stabilizing Selection. Blakiston, McGraw-Hill, New York

18. Applebaum SW, Heifetz Y 1999 Density-dependent physiological phase in insects. Annu Rev Entomol 44:317-341

19. Schlichting CD, Pigliucci M 1998 Phenotypic evolution: a reaction norm perspective. Sinauer Associates Inc., Sunderland, MA

20. Waddington CH 1957 The Strategy of the Genes: A Discussion of Some Aspects of Theoretical Biology. Macmillan, New York

21. Mayr E 2001 What Evolution Is. Basic Books, New York

22. Jablonka E, Lamb MJ 2005 Evolution in Four Dimensions: Genetic, Epigenetic, Behavioral and Symbolic Variation in the History of Life. MIT Press, Cambridge, MA

23. Maynard Smith J 1990 Models of a Dual Inheritance System. J Theor Biol 143:41-53.

24. Holliday R 1991 Mutations and Epimutations in Mammalian Cells. Mutat Res 250:351-363

25. Gluckman PD, Hanson MA, Beedle AS 2007 Non-genomic transgenerational inheritance of disease risk. Bioessays 29:145-154

26. Li E, Beard C, Jaenisch R 1993 Role for DNA methylation in genomic imprinting. Nature 366:362-365

27. Walsh CP, Chaillet JR, Bestor TH 1998 Transcription of IAP endogenous retroviruses is constrained by cytosine methylation. Nat Genet 20:116-117

28. Waterland RA, Jirtle RL 2003 Transposable elements: targets for early nutritional effects on epigenetic gene regulation. Mol Cell Biol 23:5293-5300

29. Bird A 2002 DNA methylation patterns and epigenetic memory. Genes Dev 16:6-21

30. Reik W, Dean W, Walter J 2001 Epigenetic reprogramming in mammalian development. Science 293:1089-1093

31. Yoder JA, Soman NS, Verdine GL, Bestor TH 1997 DNA (cytosine-5)methyltransferases in mouse cells and tissues. Studies with a mechanism-based probe. J Mol Biol 270:385-395

32. Gidekel S, Bergman Y 2002 A unique developmental pattern of Oct-3/4 DNA methylation is controlled by a cis-demodification element. J Biol Chem 277:3452134530

33. Hershko AY, Kafri T, Fainsod A, Razin A 2003 Methylation of HoxA5 and HoxB5 and its relevance to expression during mouse development. Gene 302:65-72

34. Grainger RM, Hazard-Leonards RM, Samaha F, Hougan LM, Lesk MR, Thomsen GH 1983 Is hypomethylation linked to activation of delta-crystallin genes during lens development? Nature 306:88-91

35. Benvenisty N, Mencher D, Meyuhas O, Razin A, Reshef L 1985 Sequential changes in DNA methylation patterns of the rat phosphoenolpyruvate carboxykinase gene during development. Proc Natl Acad Sci U S A 82:267-271 
36. Reik W, Walter J 2001 Genomic imprinting: parental influence on the genome. Nat Rev Genet 2:21-32

37. Arnaud P, Feil R 2005 Epigenetic deregulation of genomic imprinting in human disorders and following assisted reproduction. Birth Defects Res C Embryo Today 75:81-97

38. Brook JS, Whiteman M, Brook DW 1999 Transmission of risk factors across three generations. Psychol Rep 85:227-241

39. Kaati G, Bygren LO, Edvinsson S 2002 Cardiovascular and diabetes mortality determined by nutrition during parents' and grandparents' slow growth period. Eur J Hum Genet 10:682-688

40. Pembrey ME, Bygren LO, Kaati G, Edvinsson S, Northstone K, Sjostrom M, Golding J, ALSPAC Study Team 2006 Sex-specific, male-line transgenerational responses in humans. Eur J Hum Genet 14:159-166.

41. Lumey LH, Stein AD 1997 Offspring birth weights after maternal intrauterine undernutrition: a comparison within sibships. Am J Epidemiol 146:810-819

42. Painter RC, Roseboom TJ, Bleker OP 2005 Prenatal exposure to the Dutch famine and disease in later life: an overview. Reprod Toxicol 20:345-352

43. Baird DD, Newbold R 2005 Prenatal diethylstilbestrol (DES) exposure is associated with uterine leiomyoma development. Reprod Toxicol 20:81-84

44. Hatch EE, Troisi R, Wise LA, Hyer M, Palmer JR, Titus-Ernstoff L, Strohsnitter W, Kaufman R, Adam E, Noller KL, Herbst AL, Robboy S, Hartge P, Hoover RN 2006 Age at natural menopause in women exposed to diethylstilbestrol in utero. Am J Epidemiol 164:682-688

45. Palmer JR, Wise LA, Hatch EE, Troisi R, Titus-Ernstoff L, Strohsnitter W, Kaufman R, Herbst AL, Noller KL, Hyer M, Hoover RN 2006 Prenatal diethylstilbestrol exposure and risk of breast cancer. Cancer Epidemiol Biomarkers Prev 15:15091514

46. Brouwers MM, Feitz WF, Roelofs LA, Kiemeney LA, de Gier RP, Roeleveld N 2006 Hypospadias: a transgenerational effect of diethylstilbestrol? Hum Reprod 21:666-669

47. Burdge GC, Phillips ES, Dunn RL, Jackson AA, Lillycrop KA 2004 Effect of reduced maternal protein consumption during pregnancy in the rat on plasma lipid concentrations and expression of peroxisomal proliferator-activated receptors in the liver and adipose tissue of the offspring. Nutr Res 24:639-646

48. Bertram C, Trowern AR, Copin N, Jackson AA, Whorwood CB 2001 The maternal diet during pregnancy programs altered expression of the glucocorticoid receptor and type 211 beta-hydroxysteroid dehydrogenase: potential molecular mechanisms underlying the programming of hypertension in utero. Endocrinology 142:2841-2853

49. Burdge GC, Hanson MA, Slater-Jefferies JL, Lillycrop KA 2007 Epigenetic regulation of transcription: a mechanism for inducing variations in phenotype (fetal programming) by differences in nutrition during early life? Br J Nutr (in press)

50. Woods LL, Ingelfinger JR, Nyengaard JR, Rasch R 2001 Maternal protein restriction suppresses the newborn renin-angiotensin system and programs adult hypertension in rats. Pediatr Res 49:460-467

51. Champagne FA, Weaver IC, Diorio J, Dymov S, Szyf M, Meaney MJ 2006 Maternal care associated with methylation of the estrogen receptor-alphalb promoter and estrogen receptor-alpha expression in the medial preoptic area of female offspring. Endocrinology 147:2909-2915

52. Lillycrop KA, Slater-Jefferies JL, Hanson MA, Godfrey KM, Jackson AA, Burdge GC 2007 Induction of altered epigenetic regulation of the hepatic glucocorticoid receptor in the offspring of rats fed a protein-restricted diet during pregnancy suggests that reduced DNA methyltransferase-1 expression is involved in impaired DNA methylation and changes in histone modifications. Br J Nutr (in press)

53. Han HC, Austin KJ, Nathanielsz PW, Ford SP, Nijland MJ, Hansen TR 2004 Maternal nutrient restriction alters gene expression in the ovine fetal heart. J Physiol 558:111-121

54. Oliver MH, Hawkins P, Harding JE 2005 Periconceptional undernutrition alters growth trajectory and metabolic and endocrine responses to fasting in late-gestation fetal sheep. Pediatr Res 57:591-598

55. McMillen IC, Robinson JS 2005 Developmental origins of the metabolic syndrome: prediction, plasticity, and programming. Physiol Rev 85:571-633

56. Gardner DS, Tingey K, Van Bon BW, Ozanne SE, Wilson V, Dandrea J, Keisler DH, Stephenson T, Symonds ME 2005 Programming of glucose-insulin metabolism in adult sheep after maternal undernutrition. Am J Physiol Regul Integr Comp Physiol 289:R947-R954

57. Poore KR, Cleal JK, Newman JP, Boullin JP, Noakes D, Hanson MA, Green LR 2007 Nutritional challenges during development induce sex-specific changes in glucose homeostasis in the adult sheep. Am J Physiol Endocrinol Metab 292:E32E39

58. Torrens C, Brawley L, Anthony FW, Dance CS, Dunn R, Jackson AA, Poston L, Hanson MA 2006 Folate supplementation during pregnancy improves offspring cardiovascular dysfunction induced by protein restriction. Hypertension 47:982-987

59. Jackson AA, Dunn RL, Marchand MC, Langley-Evans SC 2002 Increased systolic blood pressure in rats induced by a maternal low-protein diet is reversed by dietary supplementation with glycine. Clin Sci (Lond) 103:633-639

60. Brawley L, Torrens C, Anthony FW, Itoh S, Wheeler T, Jackson AA, Clough GF, Poston L, Hanson MA 2004 Glycine rectifies vascular dysfunction induced by dietary protein imbalance during pregnancy. J Physiol 554:497-504

61. Drake AJ, Walker BR, Seckl JR 2005 Intergenerational consequences of fetal programming by in utero exposure to glucocorticoids in rats. Am J Physiol Regul Integr Comp Physiol 288:R34-R38

62. Burdge GC, Slater-Jefferies J, Torrens C, Phillips ES, Hanson MA, Lillycrop KA, 2007 Dietary protein restriction of pregnant rats in the F0 generation induces altered methylation of hepatic gene promoters in the adult male offspring in the F1 and F2 generations. Br J Nutr 97:435-439

63. Gluckman PD, Hanson MA, Spencer HG 2005 Predictive adaptive responses and human evolution. Trends Ecol Evol 20:527-533

64. Lister AM 2004 The impact of Quaternary Ice Ages on mammalian evolution. Philos Trans R Soc Lond B Biol Sci 359:221-241

65. Jablonka E, Oborny B, Molnar I, Kisdi E, Hofbauer J, Czaran T 1995 The adaptive advantage of phenotypic memory in changing environments. Philos Trans R Soc Lond B Biol Sci 350:133-141

66. Moran NA 1992 The evolutionary maintenance of alternative phenotypes. Am Nat 139:971-989

67. Sultan SE, Spencer HG 2002 Metapopulation structure favors plasticity over local adaptation. Am Nat 160:271-283

68. Gluckman PD, Hanson MA 2004 Maternal constraint of fetal growth and its consequences. Semin Fetal Neonatal Med 9:419-425

69. Kuzawa CW 1998 Adipose tissue in human infancy and childhood: an evolutionary perspective. Am J Phys Anthropol 27:177-209

70. Popkin BM 2001 Nutrition in transition: the changing global nutrition challenge. Asia Pac J Clin Nutr 10:S13-S18

71. Bhargava SK, Sachdev HS, Fall CH, Osmond C, Lakshmy R, Barker DJ, Biswas SK Ramji S, Prabhakaran D, Reddy KS 2004 Relation of serial changes in childhood body-mass index to impaired glucose tolerance in young adulthood. N Engl J Med 350:865-875

72. Prentice AM, Moore SE 2005 Early programming of adult diseases in resource poor countries. Arch Dis Child 90:429-432

73. Gluckman PD, Hanson MA 2004 The developmental origins of the metabolic syndrome. Trends Endocrinol Metab 15:183-187

74. Anway MD, Cupp AS, Uzumcu M, Skinner MK 2005 Epigenetic transgenerational actions of endocrine disruptors and male fertility. Science 308:1466-1469

75. Forsen T, Eriksson JG, Tuomilehto J, Teramo K, Osmond C, Barker DJ 1997 Mother's weight in pregnancy and coronary heart disease in a cohort of Finnish men: follow up study. BMJ 315:837-840

76. Silverman BL, Purdy LP, Metzger BE 1996 The intrauterine environment: implications for the offspring of diabetic mothers. Diabetes Rev 4:21-35

77. Aerts L, Van Assche FA 2006 Animal evidence for the transgenerational development of diabetes mellitus. Int J Biochem Cell Biol 38:894-903

78. Fraga MF, Ballestar E, Paz MF, Ropero S, Setien F, Ballestar ML, Heine-Suner D, Cigudosa JC, Urioste M, Benitez J, Boix-Chornet M, Sanchez-Aguilera A, Ling C, Carlsson E, Poulsen P, Vaag A, Stephan Z, Spector TD, Wu YZ, Plass C, Esteller M 2005 Epigenetic differences arise during the lifetime of monozygotic twins. Proc Natl Acad Sci U S A 102:10604-10609

79. Silva AJ, White R 1988 Inheritance of allelic blueprints for methylation patterns Cell 54:145-152 